\title{
PENGARUH FREKUENSI PERDAGANGAN, VOLUME PERDAGANGAN, \& KAPITALISASI PASAR TERHADAP RETURN SAHAM PADA SEKTOR PARIWISATA YANG TERDAFTAR DI BEI
}

\author{
Kristina Maysie ${ }^{1)}$ \\ Fakultas Ekonomi dan Bisnis \\ Universitas Palangka Raya, Indonesia \\ e-mail:kristina888maysie@gmail.com
}

\begin{abstract}
Abstrak
Tujuan, - Penelitian ini bertujuan untuk mengetahui seberapa besar pengaruh frekuensi perdagangan, volume perdagangan, dan kapitalisasi pasar baik secara parsial maupun simultan terhadap return saham pada sektor pariwisata yang terdaftar di BEI.

Desain/Methodologi/Pendekatan, - Penelitian ini menggunakan teknik analisis data panel (pool data) dengan menggunakan bantuan Microsoft Excel, dan Eviews 9. Sampel dalam penelitian ini adalah 4 perusahaan dari sektor pariwisata yang telah terpilih berdasarkan kriteria dengan menggunakan teknik purposive sampling.

Temuan penelitian, - Hasil penelitian menunjukkan bahwa: 1) Variabel frekuensi perdagangan berpengaruh positif dan signifikan terhadap return saham, variabel volume perdagangan dan kapitalisasi pasar berpengaruh negatif dan signifikan terhadap return saham; 2) Variabel independen (frekuensi perdagangan, volume perdagangan, dan kapitalisasi pasar) memiliki pengaruh yang signifikan terhadap variabel return saham.
\end{abstract}

Kata Kunci: Frekuensi Perdagangan, Volume Perdagangan, Kapitalisasi Pasar, dan Return Saham.

\section{The Effect of Trading Frequency, Trading Volume, \& Market Capitalization on Stock Returns in the Tourism Sector Listed on the IDX}

\begin{abstract}
Purpose, - This study aims to determine how much influence the trading frequency, trading volume, and market capitalization either partially or simultaneously on stock returns in the tourism sector listed on the IDX.

Design/methodology/approach, - This study uses panel data analysis techniques (data pool) using Microsoft Excel, and Eviews 9. Sample in this study are 4 companies from the tourism sector that have been selected based on criteria using purposive sampling technique.

Findings, - The results showed that: 1) Trading frequency variable has a positive and significant effect on stock returns, trading volume and market capitalization variables have a negative and significant effect on stock returns; 2) The independent variables (trading frequency, trading volume, and market capitalization) have a significant effect on the stock return variable.
\end{abstract}

ywords: Trading Frequency, Trading Volume, Market Capitalization, and Stock Returns.

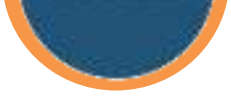

Jurnal Manajemen

Sains dan

Organisasi

Vol 2, No 1, 2021

pp. $73-84$

FEB UPR
Kristina Maysie. Published in the Jurnal Manajemen sains dan Organsasi. Published by FEB UPR Publishing Limited. This article is published under the Creative Commons Attribution (CC BY 4.0) licence. Anyone may reproduce, distribute, translate and create derivative works of this article (for both commercial and non-commercial purposes), subject to full attribution to the original publication and authors. 


\section{PENDAHULUAN}

Menurut Harsono dalam Silviyani, dkk (2014) frekuensi perdagangan adalah berapa kali transaksi jual beli terjadi pada saham yang bersangkutan pada waktu tertentu. Menurut Silviyani, dkk (2014) Saham yang memiliki frekuensi perdagangan besar diduga dipengaruhi transaksi saham yang sangat aktif, hal ini disebabkan karena banyaknya minat investor, dengan demikian dapat diketahui saham tersebut diminati investor atau tidak. Menurut Fitriyana (2014) sebuah saham dikatakan aktif diperdagangkan jika frekuensinya $\geq 75$ kali perdagangan. Hal ini berdasarkan Surat Edaran PT BEJ No. SE-03/BEJ II-1/I/1994 yang menyatakan bahwa suatu saham dikatakan aktif apabila frekuensi perdagangan saham selama 3 bulan sebanyak 75 kali atau lebih.

Jogiyanto (2010), mengatakan volume perdagangan adalah jumlah lembar saham yang diperdagangkan secara harian. Menurut Darwis (2013) perkembangan harga dan volume perdagangan saham di pasar modal merupakan suatu indikator penting untuk mempelajari tingkah laku pasar yaitu investor. Volume perdagangan yang besar menunjukkan bahwa saham tersebut sangat diminati oleh investor.

Menurut Ardiansyah (2012) kapitalisasi pasar (market capitalization) adalah perkalian antara harga pasar/harga penutupan dengan jumlah saham yang diterbitkan. Sehingga dapat disimpulkan bahwa kapitalisasi pasar merupakan nilai besaran saham yang diterbitkan oleh perusahaan. Kapitalisasi pasar yang besar umumnya menjadi salah satu daya tarik para investor dalam memilih saham.

Sebelum memutuskan untuk melakukan investasi, ada baiknya investor melakukan analisis terlebih dahulu terhadap laporan keuangan perusahaan agar dapat terhindar dari resiko yang tidak diinginkan. Investor menginvestasikan dananya dengan membeli saham pada suatu perusahaan yang tercatat di BEI untuk memperoleh return atau pendapatan dari investasi yang dilakukannya (Komala, 2013).

Berdasarkan penelitian yang telah dilakukan peneliti terdapat pergerakan yang fluktuatif pada return saham sektor pariwisata, dapat disimpulkan bahwa ada faktor yang mempengaruhi pergerakan return saham. Oleh karena itu, perlu dilakukannya analisis mengenai variabel-variabel yang mempengaruhi tingkat return pada sektor pariwisata

\section{KAJIAN PUSTAKA}

Berdasarkan tujuan penelitian, landasan teori, dan juga hasil dari beberapa penelitian sebelumnya yang mendasari setiap permasalahan yang dimunculkan dan akan di uji kebenarannya dalam penelitian yang akan dilaksanakan untuk melihat tingkat signifikan antara variabel-variabel yang terdiri dari: frekuensi perdagangan, volume perdagangan, dan kapitalisasi pasar ini apakah berpengaruh terhadap return saham. Maka dapat disusun kerangka teori sebagai berikut:

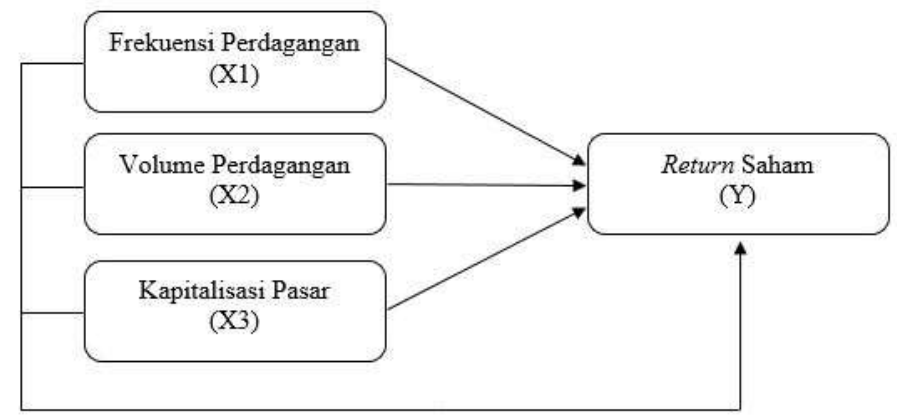

Gambar 1. Kerangka Pemikiran 


\section{Frekuensi Perdagangan (X1):}

Menurut Harsono dalam Silviyani, dkk (2014) frekuensi perdagangan adalah berapa kali transaksi jual beli terjadi pada saham yang bersangkutan pada waktu tertentu.

\section{Volume Perdagangan (X2):}

Jogiyanto (2010), mengatakan volume perdagangan adalah jumlah lembar saham yang diperdagangkan secara harian.

\section{Kapitalisasi Pasar (X3):}

Menurut Ardiansyah (2012) kapitalisasi pasar (market capitalization) adalah perkalian antara harga pasar/harga penutupan dengan jumlah saham yang diterbitkan.

\section{Return saham (Y):}

Return saham merupakan hasil yang diperoleh investor dari kegiatan investasi saham. Tandelilin (2010) mendefinisikan bahwa return adalah imbalan atas keberanian investor menanggung risiko atas investasi yang dilakukan.

\section{Hipotesis}

Penelitian ini bertujuan untuk mengetahui apakah frekuensi perdagangan, volume perdagangan, dan kapitalisasi pasar berpengaruh signifikan baik secara parsial maupun simultan terhadap return saham pada sektor pariwisata yang terdaftar di BEI.

\section{METODE PENELITIAN}

Dalam penelitian ini jenis pendekatan yang digunakan adalah pendekatan kuantitatif yang berbentuk angka dan data. Menurut Arikunto (2010), “penelitian kuantitatif sesuai dengan namanya banyak dituntut menggunakan angka, mulai dari pengumpulan data, penafsiran terhadap data tersebut, serta penampilan dari hasilnya".

Sumber data yang digunakan adalah data sekunder yaitu data yang diperoleh secara tidak langsung dengan cara mendownload data berupa laporan keuangan yang sudah di publikasi tahunan dari situs resmi Bursa Efek Indonesia yaitu www.idx.co.id beserta literatur yang berkaitan dengan penelitian kemudian data diolah dan dianalisis.

Populasi dan sampel dalam penelitian ini adalah seluruh perusahaan yang ada di sektor pariwisata yang telah terdaftar di BEI yang berjumlah 5 perusahaan, dan sampel dalam penelitian ini adalah 4 perusahaan dari sektor pariwisata yaitu: PT. Hotel Fitra Internasional Tbk (FITT), PT. Panorama Sentrawisata Tbk (PANR), PT. Pembangunan Jaya Ancol Tbk (PJAA), dan PT. Satria Mega Kencana Tbk (SOTS) yang telah terpilih berdasarkan kriteria dengan menggunakan teknik purposive sampling.

Adapun teknik analisis data yang digunakan dalam penelitian ini adalah melakukan perhitungan kuantitatif terhadap variabel-variabel penelitian yang terdiri dari frekuensi perdagangan, volume perdagangan, dan kapitalisasi pasar ini apakah berpengaruh terhadap variabel return saham yaitu dengan menggunakan data panel (pool data). Menurut Basuki dan Prawoto (2017) data panel merupakan data hasil observasi yang menggabungan antara data runtut waktu (time series) dan data silang (cross section).

Regresi data panel dapat dimodelkan sebagai berikut:

Keterangan:

$$
\mathrm{Y}_{\text {it }}=\alpha+\beta \mathrm{X}_{\text {it }}+\varepsilon_{\text {it }} ; \mathrm{i}=1,2, \ldots, \mathrm{N} ; \mathrm{t}=1,2, \ldots \ldots, \mathrm{T}
$$

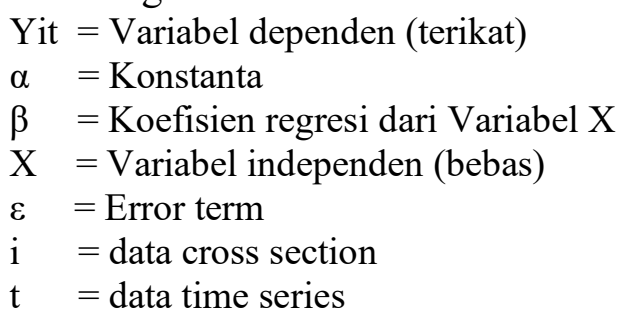


Adapun dalam pengujian asumsi klasik, tidak semua uji asumsi klasik harus dilakukan pada setiap model regresi dengan metode Ordinary Least Square/OLS (Basuki dan Prawoto, 2017). Jika pendekatan Ordinary Least Square/OLS (Common Effect Model dan Fixed Effect Model) yang terpilih maka uji asumsi klasik yang dilakukan hanya multikolinieritas dan heteroskedastisitas. Kemudian, jika pendekatan Generalized Least Squared/GLS (Random Effect Model) yang terpilih maka uji asumsi klasik yang dilakukan adalah normalitas dan multikolinieritas.

\section{HASIL DAN PEMBAHASAN}

Uji Regresi Data Panel

Terdapat tiga model yang dapat digunakan untuk melakukan regresi data panel. Ketiga model tersebut adalah Common Effect, Fixed Effect dan Random Effect.

Tabel 1. Common Effect Model

\begin{tabular}{|c|c|c|c|c|}
\hline \multicolumn{5}{|l|}{ Dependent Variable: $Y$} \\
\hline \multicolumn{5}{|c|}{ Method: Panel Least Squares } \\
\hline \multicolumn{5}{|c|}{ Date: $06 / 29 / 21$ Time: $14: 15$} \\
\hline \multicolumn{5}{|c|}{ Sample: $3 / 02 / 20206 / 29 / 2020$} \\
\hline \multicolumn{5}{|l|}{ Periods included: 76} \\
\hline \multicolumn{5}{|c|}{ Cross-sections included: 4} \\
\hline \multicolumn{5}{|c|}{ Total panel (balanced) observations: 304} \\
\hline Variable & Coefficient & Std. Error & t-Statistic & Prob. \\
\hline $\mathrm{C}$ & 103.7551 & 10.90710 & 9.512623 & 0.0000 \\
\hline $\mathrm{X} 1$ & 0.033692 & 0.070206 & 0.479901 & 0.6316 \\
\hline $\mathrm{X} 2$ & -9002.529 & 6243.713 & -1.441855 & 0.1504 \\
\hline $\mathrm{X} 3$ & 0.000000000481 & 0.0000000000282 & 17.07883 & 0.0000 \\
\hline R-squared & 0.537333 & Mean dependen & & 221.2796 \\
\hline Adjusted R-squared & 0.532707 & S.D. dependent & & 195.7903 \\
\hline S.E. of regression & 133.8400 & Akaike info criter & & 12.64424 \\
\hline Sum squared resid & 5373944. & Schwarz criterior & & 12.69315 \\
\hline Log likelihood & -1917.924 & Hannan-Quinn c & & 12.66380 \\
\hline F-statistic & 116.1383 & Durbin-Watson s & & 0.076079 \\
\hline Prob(F-statistic) & 0.000000 & & & \\
\hline
\end{tabular}

\section{Tabel 2. Fixed Effect Model}

\begin{tabular}{|c|c|c|c|c|}
\hline \multicolumn{5}{|l|}{ Dependent Variable: $Y$} \\
\hline \multicolumn{5}{|c|}{ Method: Panel Least Squares } \\
\hline \multicolumn{5}{|c|}{ Date: $06 / 29 / 21$ Time: $14: 19$} \\
\hline \multicolumn{5}{|c|}{ Sample: $3 / 02 / 20206 / 29 / 2020$} \\
\hline \multicolumn{5}{|c|}{ Periods included: 76} \\
\hline \multicolumn{5}{|c|}{ Cross-sections included: 4} \\
\hline \multicolumn{5}{|c|}{ Total panel (balanced) observations: 304} \\
\hline Variable & Coefficient & Std. Error & t-Statistic & Prob. \\
\hline & & & & \\
\hline $\mathrm{C}$ & 283.9842 & 5.820067 & 48.79397 & 0.0000 \\
\hline $\mathrm{X} 1$ & 0.086879 & 0.025955 & 3.347301 & 0.0009 \\
\hline $\mathrm{X} 2$ & -9860.185 & 2353.288 & -4.189961 & 0.0000 \\
\hline$\times 3$ & -0.000000000243 & 0.0000000000196 & -12.39275 & 0.0000 \\
\hline \multicolumn{5}{|c|}{ Effects Specification } \\
\hline \multicolumn{5}{|c|}{ Cross-section fixed (dummy variables) } \\
\hline R-squared & 0.937975 & \multicolumn{2}{|c|}{ Mean dependent var } & 221.2796 \\
\hline Adjusted R-squared & 0.936722 & \multicolumn{2}{|c|}{ S.D. dependent var } & 195.7903 \\
\hline S.E. of regression & 49.25147 & \multicolumn{2}{|c|}{ Akaike info criterion } & 10.65451 \\
\hline Sum squared resid & 720435.1 & \multicolumn{2}{|c|}{ Schwarz criterion } & 10.74010 \\
\hline Log likelihood & -1612.486 & \multicolumn{2}{|c|}{ Hannan-Quinn criter. } & 10.68875 \\
\hline F-statistic & 748.5595 & \multicolumn{2}{|c|}{ Durbin-Watson stat } & 0.230221 \\
\hline Prob(F-statistic) & 0.000000 & & & \\
\hline
\end{tabular}


Tabel 3. Random Effect Model

\begin{tabular}{|c|c|c|c|c|}
\hline \multicolumn{5}{|l|}{ Dependent Variable: $Y$} \\
\hline \multicolumn{5}{|c|}{ Method: Panel EGLS (Cross-section random effects) } \\
\hline \multicolumn{5}{|c|}{ Date: $06 / 29 / 21$ Time: 1420} \\
\hline \multicolumn{5}{|c|}{ Sample: $3 / 02 / 20206 / 29 / 2020$} \\
\hline \multicolumn{5}{|l|}{ Periods included: 76} \\
\hline \multicolumn{5}{|c|}{ Cross-sections included: 4} \\
\hline \multicolumn{5}{|c|}{ Total panel (balanced) observations: 304} \\
\hline \multicolumn{5}{|c|}{ Swamy and Arora estimator of component variances } \\
\hline Variable & Coefficient & Std. Error & t-Statistic & Prob. \\
\hline $\mathrm{C}$ & 103.7551 & 4.013677 & 25.85039 & 0.0000 \\
\hline $\mathrm{X} 1$ & 0.033692 & 0.025835 & 1.304122 & 0.1932 \\
\hline$X 2$ & -9002.529 & 2297.609 & -3.918216 & 0.0001 \\
\hline $\mathrm{X} 3$ & 0.000000000481 & 0.0000000000104 & 46.41142 & 0.0000 \\
\hline \multicolumn{5}{|c|}{ Effects Specification } \\
\hline & & & S.D. & Rho \\
\hline Cross-section random & & & 0.000000 & 0.0000 \\
\hline Idiosyncratic random & & & 49.25147 & 1.0000 \\
\hline \multicolumn{5}{|c|}{ Weighted Statistics } \\
\hline R-squared & 0.537333 & \multicolumn{2}{|c|}{ Mean dependent var } & 221.2796 \\
\hline Adjusted R-squared & 0.532707 & \multicolumn{2}{|c|}{ S.D. dependent var } & 195.7903 \\
\hline S.E. of regression & 133.8400 & \multicolumn{2}{|c|}{ Sum squared resid } & 5373944 . \\
\hline F-statistic & 116.1383 & \multicolumn{2}{|c|}{ Durbin-Watson stat } & 0.076079 \\
\hline Prob(F-statistic) & 0.000000 & & & \\
\hline \multicolumn{5}{|c|}{ Unweighted Statistics } \\
\hline R-squared & 0.537333 & \multicolumn{2}{|l|}{ Mean dependent var } & 221.2796 \\
\hline Sum squared resid & 5373944 . & \multicolumn{2}{|l|}{ Durbin-Watson stat } & 0.076079 \\
\hline
\end{tabular}

Langkah selanjutnya yang harus dilakukan adalah melakukan uji untuk memilih model mana yang terbaik diantara ketiga model diatas, yaitu dengan cara dilakukan uji Chow, uji Hausman, dan uji Lagrange Multiplier.

Tabel 4. Hasil Uji Chow Test untuk Menentukan Common Effec atau Fixed Effect

\begin{tabular}{|c|c|c|c|}
\hline \multicolumn{4}{|c|}{ Redundant Fixed Effects Tests } \\
\hline \multicolumn{4}{|l|}{ Equation: MODEL_FEM } \\
\hline \multicolumn{4}{|c|}{ Test cross-section fixed effects } \\
\hline Effects Test & Statistic & d.f. & Prob. \\
\hline Cross-section $\mathrm{F}$ & 639.471044 & $(3,297)$ & 0.0000 \\
\hline Cross-section Chi-square & 610.876461 & 3 & 0.0000 \\
\hline
\end{tabular}

Pedoman yang akan digunakan dalam pengambilan kesimpulan uji chow adalah sebagai berikut:

a. Jika nilai probability $\mathrm{F}>0,05$ artinya $H 0$ diterima; maka model common effect.

b. Jika nilai probability $\mathrm{F}<0,05$ artinya $H 0$ ditolak; maka model fixed effect, dilanjut dengan uji hausman.

\section{Interpretasi Uji Chow:}

Berdasarkan nilai probability diatas, dilihat dari Cross-section Chi-squarenya sebesar 0,0000 artinya $<0,05$, maka fixed effect model lah yang terpilih. Kemudian, dilanjut dengan uji hausman. 
Tabel 5. Hasil Uji Hausman untuk Menentukan Fixed Effect atau Random Effect

\begin{tabular}{|c|c|c|c|}
\hline \multicolumn{4}{|c|}{$\begin{array}{l}\text { Correlated Random Effects - Hausman Test } \\
\text { Equation: MODEL REM }\end{array}$} \\
\hline \multicolumn{4}{|c|}{$\begin{array}{l}\text { Equation: } 1 \text { MUDEL_REII } \\
\text { Test cross-section random effects }\end{array}$} \\
\hline Test Summary & Chi-Sq. Statistic & Chi-Sq. d.f. & Prob. \\
\hline Cross-section random & 1918.413132 & 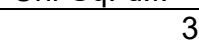 & 0.0000 \\
\hline
\end{tabular}

Pedoman yang akan digunakan dalam pengambilan kesimpulan uji chow adalah sebagai berikut:

a. Jika nilai probability $\mathrm{Chi}$-Square $>0,05$, maka $\mathrm{H} 0$ diterima, yang artinya model random effect.

b. Jika nilai probability Chi-Square $<0,05$, maka $H 0$ ditolak, yang artinya model fixed effect.

\section{Interpretasi Uji Hausman:}

Berdasarkan nilai probability diatas, dilihat dari Cross-section random nya sebesar 0,0000 artinya $<0,05$, maka fixed effect model lah yang terpilih. Setelah melakukan metode pemilihan model, dengan melalui kedua uji yaitu uji chow dan uji hausman diatas maka diperoleh lah model yang tepat untuk digunakan dalam penelitian ini adalah Model Efek Tetap (Fixed Effect Model).

\section{Uji Asumsi Klasik}

Jika pendekatan Ordinary Least Square/OLS (Common Effect Model dan Fixed Effect Model) yang terpilih, maka uji asumsi klasik yang dilakukan hanya multikolinieritas dan heteroskedastisitas (Basuki dan Prawoto, 2017).

Tabel 6. Hasil Uji Multikolinieritas

\begin{tabular}{|c|c|c|c|}
\hline & $\mathrm{X} 1$ & $\mathrm{X} 2$ & $\mathrm{X} 3$ \\
\hline & & & \\
\hline $\mathrm{X} 1$ & 1.000000 & 0.895850 & -0.021067 \\
\hline $\mathrm{X} 2$ & 0.895850 & 1.000000 & -0.158357 \\
\hline $\mathrm{X} 3$ & -0.021067 & -0.158357 & 1.000000 \\
\hline
\end{tabular}

Untuk mendeteksi ada tidaknya multikolinieritas di dalam regresi adalah dengan cara sebagai berikut :

a. Jika nilai koefisien kolerasi $(\mathrm{R} 2)>0,90$, maka data tersebut terjadi multikolinieritas.

b. Jika nilai koefisien kolerasi $(\mathrm{R} 2)<0,90$, maka data tersebut tidak terjadi multikolinieritas.

\section{Interpretasi Uji Multikolinieritas:}

Hasil pengujian dapat dilihat pada tabel 4.10 diatas, dimana nilai koefisien kolerasi antara variabel bebas masing-masing sebesar 0,89; dan -0,02<0,90, maka dapat disimpulkan bahwa antar variabel bebas (independen) tidak terjadi multikolinieritas sehingga data tersebut layak untuk diteliti.

Tabel 7. Hasil Uji Heteroskedastisitas (White Test)

\begin{tabular}{|l|c|l|l|}
\hline \multicolumn{4}{|l|}{ Heteroskedasticity Test: White } \\
\hline F-statistic & 1.790314 & Prob. F(3,300) & 0.1490 \\
\hline Obs ${ }^{\star}$ R-squared & 5.346831 & Prob. Chi-Square(3) & 0.1481 \\
\hline Scaled explained SS & 56.65662 & Prob. Chi-Square(3) & 0.0000 \\
\hline
\end{tabular}

Metode yang digunakan untuk mendeteksi heteroskedastisitas adalah white test yang dilakukan dengan meregres setiap variabel bebas dengan residual kuadrat $\left(\mathrm{e}^{2} \mathrm{i}\right)$. Jika nilai 
Prob. Chi-square yang diperoleh jauh lebih besar dari 0,05, maka model terbebas dari masalah heteroskedastisitas.

\section{Interpretasi Uji Heteroskedastisitas:}

Hasil pengujian dapat dilihat pada tabel 4.11 diatas, dimana nilai Prob. Chi-square yang diperoleh adalah sebesar 0,1481 yang artinya jauh lebih besar dari 0,05 , maka dapat disimpulkan model terbebas dari heteroskedastisitas.

\section{Uji Hipotesis}

Uji t bertujuan untuk menunjukkan seberapa besar pengaruh satu variabel (masingmasing) atau independen secara individual dalam menerangkan variabel dependen. Kriteria pengambilan keputusan sebagai berikut:

a. Jika nilai probabilitas $>$ dari 0,05 maka Ho diterima Ha ditolak, yang berarti tidak terdapat pengaruh yang signifikan antara variabel independen dengan variabel dependen.

b. Jika nilai probabilitas $<$ dari 0,05 maka Ho ditolak dan Ha diterima, yang berarti terdapat pengaruh yang signifikan antara variabel independen dengan variabel dependen.

\section{Tabel 8. Hasil Uji Parsial (Uji t)}

\begin{tabular}{|c|c|c|c|c|}
\hline \multicolumn{5}{|c|}{ Dependent Variable: Y } \\
\hline \multicolumn{5}{|c|}{ Method: Panel Least Squares } \\
\hline \multicolumn{5}{|c|}{ Date: 06/29/21 Time: $14: 19$} \\
\hline \multicolumn{5}{|c|}{ Sample: 3/02/2020 6/29/2020 } \\
\hline \multicolumn{5}{|c|}{ Periods included: 76} \\
\hline \multicolumn{5}{|c|}{ Cross-sections included: 4} \\
\hline \multicolumn{5}{|c|}{ Total panel (balanced) observations: 304} \\
\hline Variable & Coefficient & Std. Error & t-Statistic & Prob. \\
\hline $\mathrm{C}$ & 283.9842 & 5.820067 & 48.79397 & 0.0000 \\
\hline $\mathrm{X} 1$ & 0.086879 & 0.025955 & 3.347301 & 0.0009 \\
\hline $\mathrm{X} 2$ & -9860.185 & 2353.288 & -4.189961 & 0.0000 \\
\hline X3 & -0.000000000243 & 0.0000000000196 & -12.39275 & 0.0000 \\
\hline
\end{tabular}

H1:Frekuensi perdagangan berpengaruh terhadap return saham pada sektor pariwisata yang terdaftar di Bursa Efek Indonesia

Hasil pengujian dapat dilihat pada tabel 4.12 diatas, dimana nilai prob. X1 sebesar 0,0009< 0,05 yang berarti terdapat pengaruh yang signifikan antara variabel Frekuensi Perdagangan (X1) terhadap variabel Return Saham (Y) pada perusahaan sektor pariwisata yang terdaftar di Bursa Efek Indonesia. Berdasarkan hasil tersebut dapat disimpulkan bahwa hipotesis $\mathrm{H}_{1}$ diterima.

$\mathrm{H} 2$ : Volume perdagangan berpengaruh terhadap return saham pada sektor pariwisata yang terdaftar di Bursa Efek Indonesia

Hasil pengujian dapat dilihat pada tabel 4.12 diatas, dimana nilai prob. X2 sebesar $0,0000<$ 0,05 yang berarti terdapat pengaruh yang signifikan antara variabel Volume Perdagangan (X2) terhadap variabel Return Saham (Y) pada perusahaan sektor pariwisata yang terdaftar di Bursa Efek Indonesia.Berdasarkan hasil tersebut dapat disimpulkan bahwa hipotesis $\mathrm{H}_{2}$ diterima.

H3: Kapitalisasi pasar berpengaruh terhadap return saham sektor pariwisata yang terdaftar di Bursa Efek Indonesia

Hasil pengujian dapat dilihat pada tabel 4.12 diatas, dimana nilai prob. X3 sebesar $0,0000<$ 0,05 yang berarti terdapat pengaruh yang signifikan antara variabel Kapitalisasi Pasar (X3) 
terhadap variabel Return Saham (Y) pada perusahaan sektor pariwisata yang terdaftar di Bursa Efek Indonesia. Berdasarkan hasil tersebut dapat disimpulkan bahwa hipotesis $\mathrm{H}_{3}$ diterima.

Tabel 9. Hasil Uji Signifikansi Simultan (Uji F)

\begin{tabular}{|c|c|c|c|}
\hline \multicolumn{4}{|c|}{ Cross-section fixed (dummy variables) } \\
\hline R-squared & 0.937975 & Mean dependent var & 221.2796 \\
\hline Adjusted R-squared & 0.936722 & S.D. dependent var & 195.7903 \\
\hline S.E. of regression & 49.25147 & Akaike info criterion & 10.65451 \\
\hline Sum squared resid & 720435.1 & Schwarz criterion & 10.74010 \\
\hline Log likelihood & -1612.486 & Hannan-Quinn criter. & 10.68875 \\
\hline F-statistic & 748.5595 & Durbin-Watson stat & 0.230221 \\
\hline Prob(F-statistic) & 0.000000 & & \\
\hline
\end{tabular}

Uji F bertujuan untuk menunjukkan apakah semua variabel independen mempunyai pengaruh secara bersama-sama terhadap variabel dependen atau terikat. Kriteria pengambilan keputusan sebagai berikut:

a. Ho diterima jika tingkat signifikansi $>0,05$

b. Ha diterima jika tingkat signifikansi $<0,05$

H4: Frekuensi perdagangan, volume perdagangan, dan kapitalisasi pasar berpengaruh secara simultan terhadap return saham pada sektor pariwisata yang terdaftar di Bursa Efek Indonesia. Hasil pengujian dapat dilihat pada tabel 4.13 diatas, dimana nilai prob(F-statistic) sebesar $0,000000<0,05$ yang berarti variabel Frekuensi Perdagangan (X1), Volume Perdagangan (X2), dan Kapitalisasi Pasar (X3) secara bersama-sama (simultan) berpengaruh signifikan terhadap variabel Return Saham (Y) pada perusahaan sektor pariwisata yang terdaftar di Bursa Efek Indonesia. Berdasakan hasil tersebut dapat disimpulkan bahwa hipotesis $\mathrm{H}_{4}$ diterima.

Koefisien Determinasi

Tabel 10. Hasil Uji Koefisien Determinasi

\begin{tabular}{|l|l|l|l|}
\hline \multicolumn{4}{|l|}{ Cross-section fixed (dummy variables) } \\
\hline R-squared & 0.937975 & Mean dependent var & 221.2796 \\
\hline Adjusted R-squared & 0.936722 & S.D. dependent var & 195.7903 \\
\hline S.E. of regression & 49.25147 & Akaike info criterion & 10.65451 \\
\hline Sum squared resid & 720435.1 & Schwarz criterion & 10.74010 \\
\hline Log likelihood & -1612.486 & Hannan-Quinn criter. & 10.68875 \\
\hline F-statistic & 748.5595 & Durbin-Watson stat & 0.230221 \\
\hline Prob(F-statistic) & 0.000000 & & \\
\hline
\end{tabular}

\section{Interpretasi Uji Koefisien Determinasi:}

Hasil pengujian dapat dilihat pada tabel 4.14 diatas, dimana nilai Adjusted R-squared sebesar 0,93 (93\%) yang memberikan makna bahwa variabel Return Saham dapat dijelaskan oleh variabel Frekuensi Perdagangan (X1), Volume Perdagangan (X2), dan Kapitalisasi Pasar (X3) sebesar 93\%, sedangkan sisanya sebesar 7\% dijelaskan oleh variabel lain yang tidak terkait dalam penelitian ini.

\section{Pembahasan}

Tabel 11. Hasil Regresi Data Panel (Fixed Effect Model)

\begin{tabular}{|l|}
\hline Dependent Variable: $Y$ \\
\hline Method: Panel Least Squares \\
\hline Date: $06 / 29 / 21$ Time: $14: 19$ \\
\hline Sample: $3 / 02 / 2020$ 6/29/2020 \\
\hline Periods included: 76 \\
\hline Cross-sections included: 4 \\
\hline
\end{tabular}




\begin{tabular}{|c|c|c|c|c|}
\hline Total panel (balanced) observations: 304 & & & \\
\hline & & & & \\
\hline Variable & Coefficient & Std. Error & t-Statistic & Prob. \\
\hline C & 283.9842 & 5.820067 & 48.79397 & 0.0000 \\
\hline X1 & 0.086879 & 0.025955 & 3.347301 & 0.0009 \\
\hline X2 & -9860.185 & 2353.288 & -4.189961 & 0.0000 \\
\hline X3 & -0.000000000243 & 0.0000000000196 & -12.39275 & 0.0000 \\
\hline \multicolumn{5}{|c|}{ Effects Specification } \\
\hline Cross-section fixed (dummy variables) \\
\hline \multicolumn{5}{|l|}{} \\
\hline R-squared & 0.937975 & Mean dependent var & 221.2796 \\
\hline Adjusted R-squared & 0.936722 & S.D. dependent var & 195.7903 \\
\hline S.E. of regression & 49.25147 & Akaike info criterion & 10.65451 \\
\hline Sum squared resid & 720435.1 & Schwarz criterion & 10.74010 \\
\hline Log likelihood & -1612.486 & Hannan-Quinn criter. & 10.68875 \\
\hline F-statistic & 748.5595 & Durbin-Watson stat & 0.230221 \\
\hline Prob(F-statistic) & 0.000000 & & \\
\hline
\end{tabular}

Hasil perolehan untuk analisis regresi data panel sebagai berikut:

$\mathrm{Y}=283,9842$ it $+0,086879 \mathrm{X}_{1 \text { it }}-9860,185 \mathrm{X}_{2}$ it $-0.000000000243 \mathrm{X}_{3 \text { it }}+\varepsilon_{\text {it }}$

Berdasarkan model fixed effect diatas maka hasil regresi data panel dapat ditarik kesimpulan sebagai berikut:

a. Nilai konstanta sebesar 283,9842 artinya jika variabel FP $\left(\mathrm{X}_{1}\right)$, VP $\left(\mathrm{X}_{2}\right)$, dan $\mathrm{KP}\left(\mathrm{X}_{3}\right)$ nilainya adalah 0, maka Persentase Return Saham (Y) nilainya adalah 283,9842\%.

b. Nilai koefisien regresi variabel FP $\left(\mathrm{X}_{1}\right)$ sebesar 0,086879. Artinya, jika hasil penelitian variabel $\mathrm{FP}\left(\mathrm{X}_{1}\right)$ ke i pada waktu $\mathrm{t}$ adalah konstan atau tetap, maka return saham akan mengalami peningkatan sebesar 0,086879 .

c. Nilai koefisien regresi variabel VP $\left(\mathrm{X}_{2}\right)$ sebesar $-9860,185$. Artinya, jika hasil penelitian variabel VP $\left(\mathrm{X}_{2}\right)$ ke i pada waktu $\mathrm{t}$ adalah konstan atau tetap, maka return saham akan mengalami penurunan sebesar $-9860,185$.

d. Nilai koefisien regresi variabel KP $\left(\mathrm{X}_{3}\right)$ sebesar -0.000000000243. Artinya, jika hasil penelitian variabel $\mathrm{KP}\left(\mathrm{X}_{3}\right)$ ke i pada waktu t adalah konstan atau tetap, maka return saham akan mengalami penurunan sebesar -0.000000000243 .

\section{Pengujian Hipotesis}

\section{Pengaruh Frekuensi Perdagangan Terhadap Return Saham}

Hasil penelitian ini yang dijelaskan pada tabel 4.12 menunjukkan bahwa variabel frekuensi perdagangan $\left(\mathrm{X}_{1}\right)$ berpengaruh positif dan signifikan terhadap variabel return saham (Y). Hasil penelitian dapat dibuktikan melalui nilai probabilitas sebesar 0,0009<0,05 dan menghasilkan koefisien regresi yang positif yaitu sebesar 0,086879 . Artinya menolak Ho dan menerima Ha.

Hasil penelitian ini mendukung penelitian terdahulu yaitu salah satunya yang telah dilakukan oleh Taslim (2015) yang menyatakan bahwa frekuensi perdagangan berpengaruh positif signifikan terhadap return saham. Menurut Silviyani, dkk (2014) saham yang memiliki frekuensi perdagangan besar diduga dipengaruhi transaksi saham yang sangat aktif, hal ini disebabkan karena banyaknya minat investor, dengan demikian dapat diketahui saham tersebut diminati investor atau tidak. Dengan meningkatnya jumlah frekuensi transaksi perdagangan yang disebabkan permintaan yang tinggi maka harga saham akan terdorong naik sehingga return saham juga akan meningkat (Taslim dan Wijayanto, 2016)

\section{Pengaruh Volume Perdagangan Terhadap Return Saham}

Hasil penelitian ini yang dijelaskan pada tabel 4.12 menunjukkan bahwa variabel 
volume perdagangan $\left(\mathrm{X}_{2}\right)$ berpengaruh negatif dan signifikan terhadap variabel return saham (Y). Hasil penelitian dapat dibuktikan melalui nilai probabilitas sebesar 0,0000<0,05 dan menghasilkan koefisien regresi yang negatif sebesar -9860,185. Artinya menolak Ho dan menerima Ha.

Hasil penelitian ini juga sesuai dengan penelitian yang dilakukan oleh (Chen et all, 2001; didalam Ernanto, 2016) yang menyatakan bahwa tidak selalu ditemukan hubungan kausal antara variabel volume perdagangan dengan return saham. Hal ini mengindikasikan bahwa saham yang memiliki volume perdagangan yang tinggi dan saham tersebut dinyatakan sebagai saham yang aktif diperdagangkan tidak menjamin perusahaan tersebut menghasilkan return saham yang tinggi (Novirman, 2019).

\section{Pengaruh Kapitalisasi Pasar Terhadap Return Saham}

Hasil penelitian ini yang dijelaskan pada tabel 4.12 menunjukkan bahwa variabel kapitalisasi pasar $\left(\mathrm{X}_{3}\right)$ berpengaruh negatif dan signifikan terhadap variabel return saham $(\mathrm{Y})$. Hasil penelitian dapat dibuktikan melalui nilai probabilitas sebesar 0,0000<0,05 dan menghasilkan koefisien regresi yang negatif sebesar $-0,000000000243$. Artinya menolak Ho dan menerima Ha.

Hasil penelitian ini mendukung penelitian terdahulu yang dilakukan oleh Ernanto (2016) yang menyatakan bahwa kapitalisasi pasar berpengaruh negatif dan signifikan terhadap return saham. Hasil penelitian menyatakan bahwa kenaikan kapitalisasi pasar justru akan membuat return saham menurun.

\section{Pengaruh Frekuensi Perdagangan, Volume Perdagangan, dan Kapitalisasi Pasar Secara Simultan Terhadap Return Saham}

Hasil penelitian ini yang dijelaskan pada tabel 4.13 menunjukkan bahwa variabel Frekuensi Perdagangan (X1), Volume Perdagangan (X2), dan Kapitalisasi Pasar (X3) secara bersama-sama (simultan) berpengaruh signifikan terhadap variabel Return Saham (Y) pada perusahaan sektor pariwisata yang terdaftar di Bursa Efek Indonesia. Hasil penelitian dapat dibuktikan melalui nilai prob (F-statistic) sebesar $0,000000<0,05$. Artinya menolak Ho dan menerima Ha. Hasil penelitian ini mendukung penelitian terdahulu yang dilakukan oleh Maknun (2010) yang menyatakan bahwa frekuensi perdagangan, volume perdagangan dan kapitalisasi pasar secara bersama-sama (simultan) memiliki pengaruh yang signifikan terhadap return saham.

\section{KESIMPULAN DAN SARAN}

Hasil penelitian menunjukkan bahwa: 1) Secara parsial dengan uji-t menyatakan bahwa variabel frekuensi perdagangan (X1) berpengaruh positif dan signifikan terhadap return saham, variabel volume perdagangan (X2) dan kapitalisasi pasar (X3) berpengaruh negatif dan signifikan terhadap return saham; 2) secara simultan dengan uji-F menyatakan bahwa variabel independen (frekuensi perdagangan, volume perdagangan, dan kapitalisasi pasar) memiliki pengaruh yang signifikan terhadap variabel return saham (Y).

\section{Saran}

Berdasarkan hasil penelitian yang telah dilakukan, ada beberapa saran yang dapat dipertimbangkan untuk penelitian selanjutnya, yaitu:

- Penelitian ini dapat menjadi tambahan referensi dan mampu memberikan kontribusi dalam menyusun penelitian-penelitian selanjutnya. Untuk itu, penulis memberikan saran bagi peneliti selanjutnya agar dapat menggunakan variabel lain yang dianggap memiliki pengaruh terhadap return saham, menggunakan metode penelitian yang berbeda, serta 
dapat menambahkan periode penelitian yang lebih banyak agar mendapatkan hasil yang baik dan akurat.

- Untuk penelitian selanjutnya diharapkan agar mendapatkan suatu model penelitian yang baik dengan didukung oleh teori yang kuat serta disarankan untuk memperbanyak referensi penelitian yang dapat mendukung topik yang diteliti.

\section{DAFTAR PUSTAKA}

Afif Aulia Novirman., (2019). Pengaruh Volume Perdagangan, Frekuensi Perdagangan, Kapitalisasi Pasar, Dan Dividend Payout Ratio Terhadap Return Saham Jakarta Islamic Index. Diakses pada 30 Mei 2020

Agus Tri Basuki and Prawoto, Nano. 2017. Analisis Regresi Dalam Penelitian Ekonomi \& Bisnis: Dilengkapi Aplikasi SPSS \& EVIEWS. PT Rajagrafindo Persada, Depok.

Ahmad Taslim., (2015). Pengaruh Frekuensi Perdagangan Saham, Volume Perdagangan Saham, Kapitalisasi Pasar dan Jumlah Hari Perdagangan Terhadap Return Saham (Studi Pada Saham Perusahaan Dagang Eceran Yang Terdaftar Dalam Indeks Saham Syariah Indonesia Sebelum Sampai Sesudah Bulan Ramadhan Periode 2012-2014). Diakses pada 17 April 2020

Ang, Robert. 1997. Buku Pintar Pasar Modal Indonesia Edisi I, Media Soft, Indonesia

Anggita Permata Yakup. (2019). Pengaruh Sektor Pariwisata Terhadap Pertumbuhan Ekonomi Indonesia. Diakses pada 13 September 2020

Andhi Wijayanto \& Ahmad Taslim., (2016). Pengaruh Frekuensi Perdagangan Saham, Volume Perdagangan Saham, Kapitalisasi Pasar dan Jumlah Hari Perdagangan Terhadap Return Saham. Management Analysis Journal 5 (1) (2016), http://maj.unnes.ac.id. Diakses pada 17 April 2020

A. Patoni, A. Lasmana., (2015). Pengaruh Harga Saham Dan Frekuensi Perdagangan Saham Terhadap Bid-Ask Spread (Studi Empiris Pada Perusahaan Manufaktur Yang Melakukan Stock Split Di Bursa Efek Indonesia Selama Periode 2009-2014. JURNAL AKUNIDA ISSN 2442-3033 Volume 1 Nomor 2, Desember 2015. Diakses pada $30 \mathrm{Mei}$ 2020

Arikunto, S. (2010). Prosedur penelitian: Suatu Pendekatan Praktik. Jakarta: Rineka Cipta.

Ardiansyah. (2012). Analisis Pengaruh Faktor Fundamental Dan Nilai Kapitalisasi Pasar Terhadap Return Saham. Jurnal Ilmiah Mahasiswa FEB Universitas Brawijaya Vol 1, No 2: Semester Genap 2012/2013. Diakses pada 02 September 2020

Darwis, Saputra. (2013). Pengaruh Volume Perdagangan Terhadap Return Saham LQ-45 Selama Bulan Ramadhan di BEI. Jurnal Jurusan Management STIE MDP. eprints.mdp.ac.id/761/1/JURNAL_2009200001_Darwis.pdf. Diakses pada 02 September 2020

Ernanto., (2016). Pengaruh Frekuensi Perdagangan, Volume Perdagangan, dan Kapitalisasi Pasar Terhadap Return Saham Pada Perusahaan Manufaktur Yang Terdaftar Di BEI. Diakses pada 17 April 2020

Fitriyana., (2014). Analisis Pengaruh Frekuensi Perdagangan, Volume Perdagangan, Kapitalisasi Pasar, Hari Perdagangan dan Laba Terhadap Return Saham (Studi Empiris pada Perusahaan Manufaktur yang Terdaftar di BEI. Diakses pada 17 April 2020

Fira Aprilia. (2018). Pengaruh Return On Assets, Net Profit Margin, Earning Per Share Dan Debt To Equity Ratio Terhadap Return Saham Pada Industri Hotel, Restoran \& Pariwisata Yang Terdaftar Di Bursa Efek Indonesia. Diakses Pada 13 September 2020

Ghozali, Imam. (2013). Aplikasi Analisis Multivariat dengan Program IBM SPSS. Edisi 7. Semarang: Penerbit Universitas Diponegoro.

Halim, Abdul. (2003). Analisis Investasi, Salemba Empat, Jakarta 
Hanafi Mamduh M. (2016). Manajemen Keuangan. Yogyakarta: BPFE Yogyakarta

Hanafi Mamduh M. Abdul Halim. (2016). Analisis Laporan Keuangan. Yogyakarta: UPP STIM YKPN

Husnan, Suad. (1998). Dasar-Dasar Portofolio dan Analisis Sekuritas, UPP-AMP YKPN, Yogyakarta.

Jogiyanto H.M. (2010). Teori Portofolio dan Analisis Investasi. Edisi Ketujuh. Yogyakarta: BPFE

Jogiyanto, Hartono. (2013). Teori dan Analisis Investasi. Edisi Kedelapan. Yogyakarta; BPFE.

Latif Zubaidah Nasution. Pengaruh Volume Perdagangan Saham, Frekuensi Perdagangan Saham, Volatilitas Harga Saham, Dan Kapitalsiasi Pasar Terhadap Return Saham Perusahaan Makananan Dan Minuman Yang Terdaftar Di Bursa Efek Indonesia. Journal Riset Mahasiswaxxxxxxx (JRMx). ISSN:2337-56xx. Volume:xx, Nomor:xx. Diakses pada 02 September 2020

Lu'luil Maknun., (2010). Analisis Pengaruh Frekuensi Perdagangan, Volume Perdagangan, Kapitalisasi Pasar, dan Trading Day Terhadap Return Saham Pada Perusahaan Manufaktur Yang Terdaftar Di BEI Periode Tahun 2006-2008. Diakses pada 17 April 2020

Muhammad Yusra., (2019). Pengaruh Frekuensi Perdagangan, Trading Volume, Nilai Kapitalisasi Pasar, Harga Saham, Dan Trading Day Terhadap Return Saham Pada Perusahaan Makanan dan Minuman Di Bursa Efek Indonesia. Jurnal Akuntansi Dan Keuangan, ISSN : 2301-4717, Volume 7, Nomor 1, Februari 2019, p. 65-74. Diakses pada 17 April 2020

Muhammad Arish Munajat, (2015). Pengaruh Leverage Dan Financial Distress Terhadap Konservatisme Akuntansi Universitas Pendidikan Indonesia. /upi.edu perpustakaan.upi.edu. Diakses pada 03 September 2020

Silviyani, dkk. (2014). Pengaruh Likuiditas Perdagangan Saham dan Kapitalisasi Pasar Terhadap Return Saham Perusahaan Yang Berada Pada Indeks Lq45 Di Bursa Efek Indonesia Periode Tahun 2009-2013 (Studi Empiris Pada Perusahaan Lq45 Di Bursa Efek Indonesia). e-Journal S1 Ak Universitas Pendidikan Ganesha Jurusan Akuntansi SI (Volume: 2 No. 1 Tahun 2014). Diakses pada 02 September 2020

Styfanda Pangestika, (2015). Analisis Estimasi Model Regresi Data Panel dengan Pendekatan Common Effect Model (CEM), Fixed Effect Model (FEM), dan Random Effect Model (REM). Diakses pada 03 September 2020

Sugiyono. (2011). Metode Penelitian Kuantitatif, Kualitatif dan R\&D. Bandung: Afabeta

Sunariyah. (2010). Pengantar Pengetahuan Pasar Modal, Edisi keenam. UPP STIM YKPN: Yogyakarta.

Tandelilin, E. (2010). Portofolio \& Investasi: Teori \& Aplikasi, Edisi Pertama. Yogyakarta: Kanisius.

Yahya, Lucky Mahesa. (2008). Pengaruh Aktivitas Perdagangan Saham Terhadap Nilai PER ( price earning ratio) dan Tingkat Pengembalian Saham Pada Industri Manufaktur Yang Terdaftar Di Bei (Bursa Efek Indonesia) dalam Periode Tahun 2004 Sampai dengan Tahun 2007.2 universitasandalas. repository.unand.ac.id/2222/1/6._artikel_lucky_hal_84-105.doc. Diakses pada 02 September 2020

https://www.sahamok.com/emiten/sektor-perdagangan-jasa-investasi/sub-sektor-hotelrestoran-pariwisata/ (diakses pada 30 Mei 2020)

https://www.idx.co.id/ (diakses pada 20 April 2020) 